\title{
Chemoenzymatic Assembly of Isotopically Labeled Folates
}

\author{
Antonio Angelastro, William M. Dawson, ${ }^{\dagger}{ }^{\circledR}$ Louis Y. P. Luk, E. Joel Loveridge, ${ }^{\ddagger ৫}$ \\ and Rudolf K. Allemann*(i) \\ School of Chemistry, Cardiff University, Park Place, Cardiff CF10 3AT, United Kingdom
}

Supporting Information

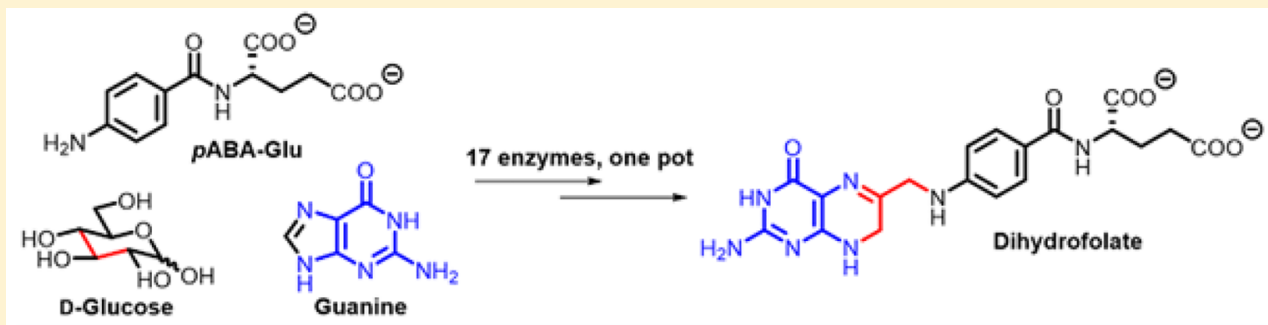

$>91 \%$ average yield per step

ABSTRACT: Pterin-containing natural products have diverse functions in life, but an efficient and easy scheme for their in vitro synthesis is not available. Here we report a chemoenzymatic 14-step, one-pot synthesis that can be used to generate ${ }^{13} \mathrm{C}$ - and ${ }^{15} \mathrm{~N}$-labeled dihydrofolates $\left(\mathrm{H}_{2} \mathrm{~F}\right)$ from glucose, guanine, and $p$-aminobenzoyl-L-glutamic acid. This synthesis stands out from previous approaches to produce $\mathrm{H}_{2} \mathrm{~F}$ in that the average yield of each step is $>91 \%$ and it requires only a single purification step. The use of a one-pot reaction allowed us to overcome potential problems with individual steps during the synthesis. The availability of labeled dihydrofolates allowed the measurement of heavy-atom isotope effects for the reaction catalyzed by the drug target dihydrofolate reductase and established that protonation at $\mathrm{N} 5$ of $\mathrm{H}_{2} \mathrm{~F}$ and hydride transfer to C6 occur in a stepwise mechanism. This chemoenzymatic pterin synthesis can be applied to the efficient production of other folates and a range of other natural compounds with applications in nutritional, medical, and cell-biological research.

\section{INTRODUCTION}

Pterin is a common motif found in natural products. Folate, the essential vitamin that fuels the one-carbon cycle for the biosynthesis of nucleotide and amino acid building blocks, was one of the first natural products found to contain pterin., The metabolic importance of pterins is illustrated by their integration into enzyme cofactors such as molybdopterin and tetrahydrobiopterin. ${ }^{3-5}$ Pterin natural products are also used as pigments in the butterflies Catopsilia argante and Appias nero, ${ }^{6}$ whereas biopterin- $\alpha$-glucoside serves as a natural sunscreen that protects cellular contents from photoinduced damage in photosynthetic cyanobacteria. $^{7}$

$5,6,7,8$-Tetrahydrofolic acid $\left(\mathrm{H}_{4} \mathrm{~F}\right)$, which in addition to the pterin ring system contains $p$-aminobenzoic acid ( $p A B A)$ and L-glutamic acid (Glu), is required for the biosynthesis of metabolites that are key for cell survival and replication. ${ }^{2}$ A one-carbon unit in different oxidation states can be added at $\mathrm{N} 5$ and/or N10 of $\mathrm{H}_{4} \mathrm{~F}$ and used to produce metabolites such as thymidylate, purines, glycine, serine, and $S$-adenosylmethionine (SAM) (Figure 1). ${ }^{8}$ Because of the central importance of folate biochemistry for cell replication and survival, dihydrofolate reductase (DHFR), thymidylate synthase (TS), and serine hydroxymethyltransferase (SHMT) have long been exploited as important drug targets in the treatment of bacterial infections, ${ }^{9}$ malaria, ${ }^{10,11}$ and cancer, ${ }^{12,13}$ and the DHFR-targeting drugs trimethoprim, proguanil, pyrimethamine, and methotrexate are listed as essential medicines by the World Health Organization (WHO). ${ }^{14}$ Nevertheless, as with many clinically used drugs, resistance to antifolates has begun to emerge, ${ }^{15-17}$ and investigation of the enzymes of the one-carbon cycle is an important part of inhibitor design strategies. ${ }^{18}$

Detailed mechanistic insight into enzyme-catalyzed reactions is often obtained by isotopic labeling and measurement of kinetic isotope effects (KIEs) $)^{19-22}$ or spectroscopic analysis. ${ }^{23,24}$ Information derived from regio- and stereospecific substrate labeling has been used to design inhibitors with dissociation constants in the micro- to picomolar range. ${ }^{25}$ However, the use of these techniques to investigate folate-dependent enzymes is hindered by the absence of a general and efficient method to specifically label atoms of the pterin ring system, particularly at N5, C6, C7, and C9, which are directly linked to the chemistry of the catalyzed reactions. Folate and its derivatives can be synthesized by connecting the pterin, $p A B A$, and glutamate groups in sequential order, ${ }^{26}$ and several synthetic strategies to incorporate an isotopic label into pterin in a regiospecific manner have been reported. ${ }^{27-30}$ Pterins have been synthesized by condensing guanidine or dihydroxyacetone with the respective heterocyclic starting materials, and N5-, C2-, and C6-labeled folates have been made previously. ${ }^{27,28}$ However, because symmetric

Received: June 19, 2017

Published: August 18, 2017 


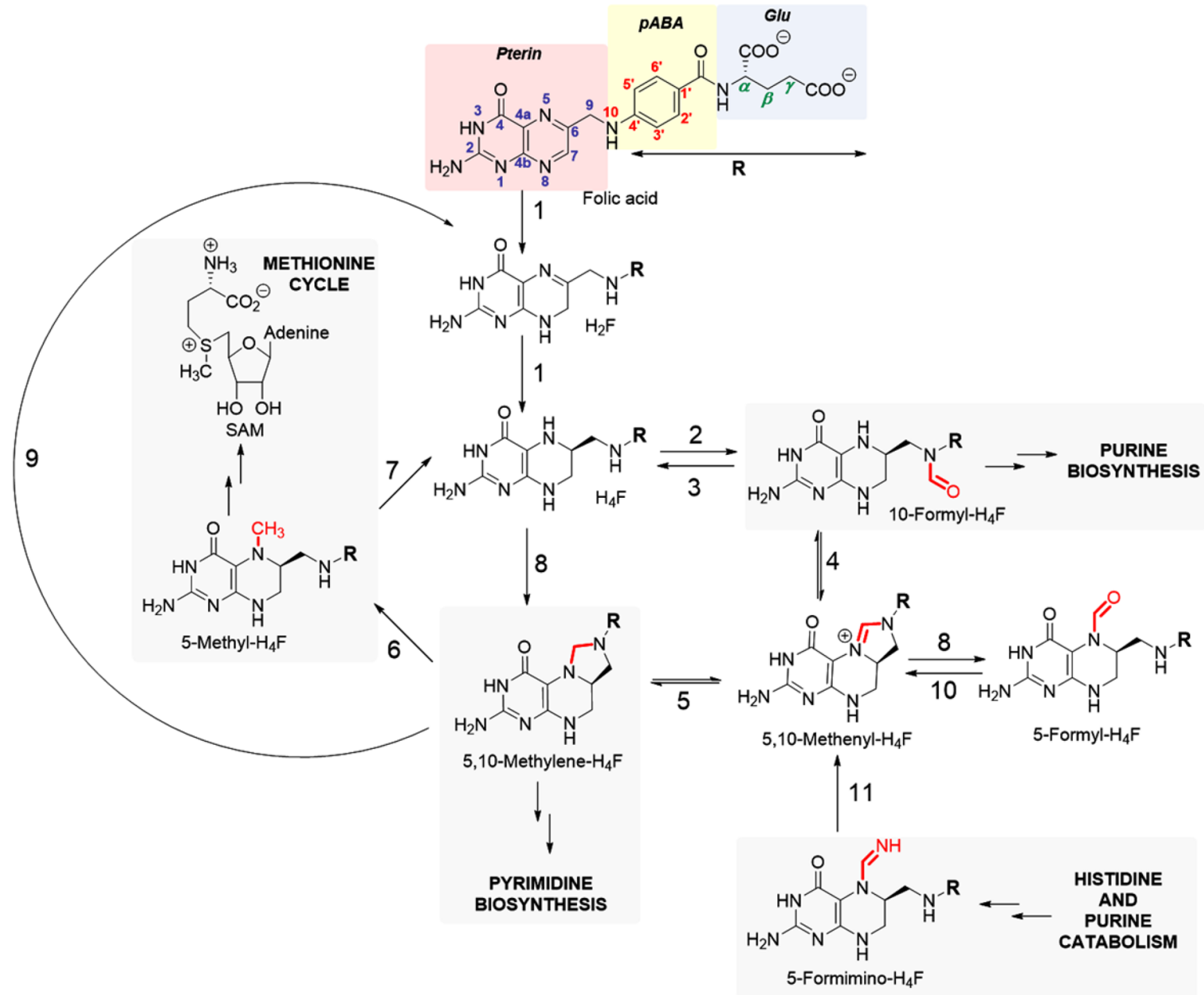

Figure 1. Folate coenzymes in one-carbon metabolism. Folic acid is converted to 7,8-dihydrofolic acid $\left(\mathrm{H}_{2} \mathrm{~F}\right)$ and 5,6,7,8-tetrahydrofolic acid $\left(\mathrm{H}_{4} \mathrm{~F}\right)$. One-carbon units attached to $\mathrm{H}_{4} \mathrm{~F}$ are highlighted. Abbreviations: 1, dihydrofolate reductase (DHFR); 2, 10-formyl- $\mathrm{H}_{4} \mathrm{~F}$ synthetase (FTHFS); 3, 10-formyl- $\mathrm{H}_{4} \mathrm{~F}$ dehydrogenase (FDH); 4, 5,10-methenyl- $\mathrm{H}_{4} \mathrm{~F}$ cyclohydrolase (MTHFC); 5, 5,10-methylene- $\mathrm{H}_{4} \mathrm{~F}$ dehydrogenase (MTHFD); 6, 5,10-methylene- $\mathrm{H}_{4} \mathrm{~F}$ reductase (MTHFR); 7, methionine synthase (MS); 8, serine hydroxymethyltransferase (SHMT); 9, thymidylate synthase (TS); 10, 5,10-methenyl- $\mathrm{H}_{4} \mathrm{~F}$ synthetase (MTHFS); 11, 5-formimino- $\mathrm{H}_{4} \mathrm{~F}$ cyclodeaminase (FTCD); SAM, S-adenosylmethionine.

reagents are used in these syntheses, regioselective isotope labeling of $\mathrm{C} 7$ and $\mathrm{C} 9$ cannot easily be achieved. ${ }^{28,30}$ In all cases, the yields of labeled folate or derivatives are low $(<5 \%$ overall yield), and the procedures depend on multiple purification steps. Chemoenzymatic strategies have also been described, ${ }^{31-33}$ whereby $\mathrm{H}_{4} \mathrm{~F}$ was condensed with ${ }^{11} \mathrm{C}$-formaldehyde or ${ }^{14} \mathrm{C}$-formic acid to yield the corresponding isotopically labeled $\left[{ }^{11} \mathrm{C}\right] 5,10$-methylene- $\mathrm{H}_{4} \mathrm{~F},\left[{ }^{14} \mathrm{C}\right] 5$-formyl- $\mathrm{H}_{4} \mathrm{~F}$, and $\left[{ }^{14} \mathrm{C}\right] 10$-form$\mathrm{yl}-\mathrm{H}_{4} \mathrm{~F}$. However, a general and efficient method to label the pterin ring in folates has never been developed.

In nature, the pterin ring in folate is formed from guanosine triphosphate (GTP) in one biochemical step catalyzed by GTP cyclohydrolase (GTP-CH), ${ }^{34,35}$ an enzyme found in all kingdoms of life ranging from archaebacteria, insects, plants to humans. In all GTP-CH-catalyzed reactions, GTP is converted to a pterin via a set of tandem reactions that have no equivalent in organic chemistry. GTP cyclohydrolase I (GTP-CH-I) catalyzes the formation of 7,8-dihydroneopterin triphosphate (DHNTP) from GTP by mediating four distinct chemical reactions (Figure S1): hydrolysis of the purine ring yielding an $\mathrm{N}$-formyl intermediate, $\mathrm{N}$-deformylation, a stereospecific Amadori rearrangement of the ribose moiety, and ring closure to form the pterin. ${ }^{36-38}$ Because no symmetric reagent is used in this reaction, GTP-CH-I can be used to synthesize the pterin ring system of folate with heavy isotopes incorporated regio- and stereoselectively. ${ }^{39}$ It is therefore surprising that GTP-CH-I has not been used in any in vitro enzymatic pathway to synthesize folates. Perhaps the low catalytic turnover $\left(k_{\text {cat }}=0.05 \mathrm{~s}^{-1}\right)^{40}$ and the rather low stability of the product 7,8-dihyropterin ${ }^{41}$ toward oxygen and light have limited the use of GTP-CH-I in synthesis.

Here we report a 14-step one-pot chemoenzymatic synthesis of 7,8-dihydrofolic acid $\left(\mathrm{H}_{2} \mathrm{~F}\right)$ that exploits the well-established procedures to isotopically label GTP $\mathrm{GP}^{39,42,43}$ by using GTP-CH-I to site-specifically isotope-label pterins. The low enzymatic activity and product instability of GTP-CH-I were addressed by enzymatic coupling. By means of our methodology, $\mathrm{H}_{2} \mathrm{~F}$ enriched with stable isotopes at N5 and C6 could be synthesized efficiently in pure form in $>30 \%$ yield from isotopically enriched D-glucose and guanine. Given the high degree of purity and isotopic enrichment (>97\%; see the Supporting Information), heavy-atom KIEs could be measured to investigate the mechanism of the Escherichia coli DHFR (EcDHFR)-catalyzed reduction of $\mathrm{H}_{2} \mathrm{~F}$ to $\mathrm{H}_{4} \mathrm{~F}$.

\section{RESULTS AND DISCUSSION}

In Vitro Synthesis of Folate. The biosynthetic pathway to folate in E. coli uses the building blocks D-glucose, guanine, and 


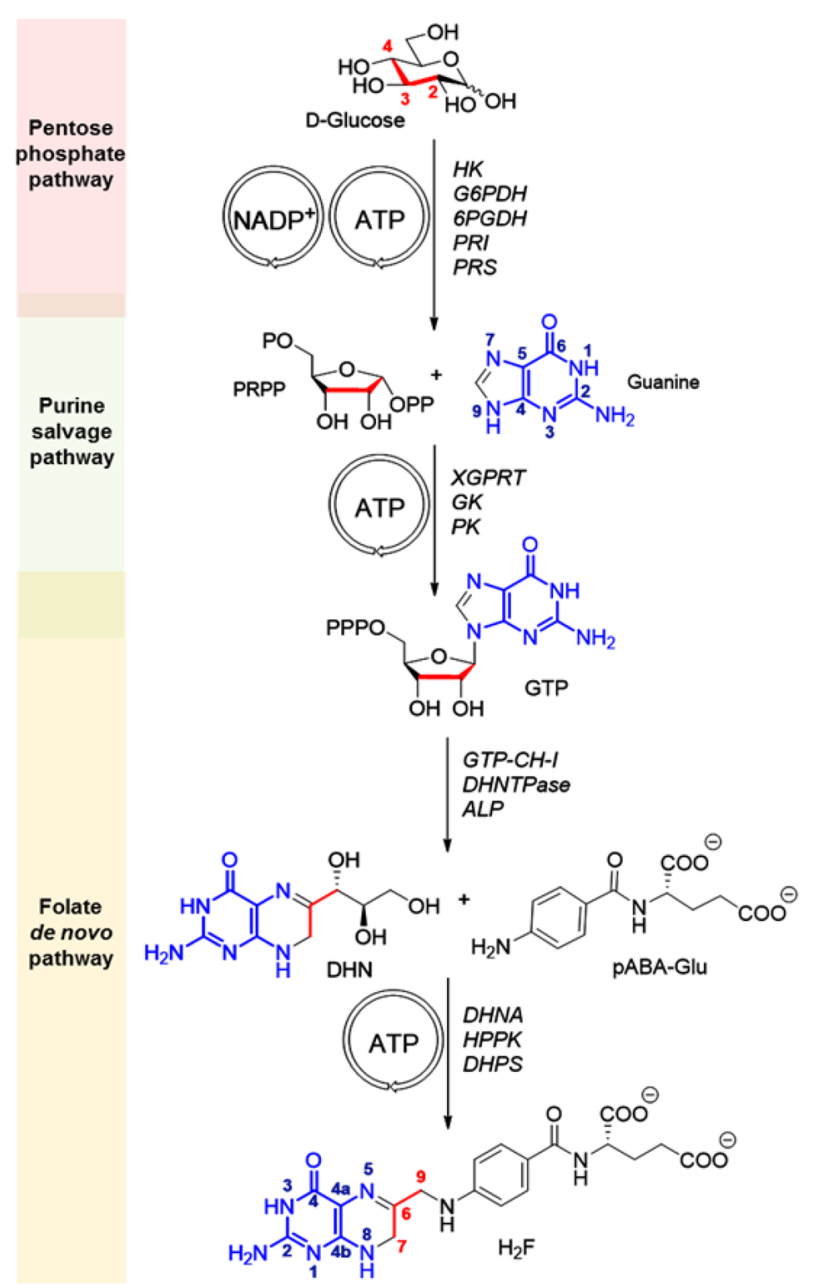

Cofactor regeneration system
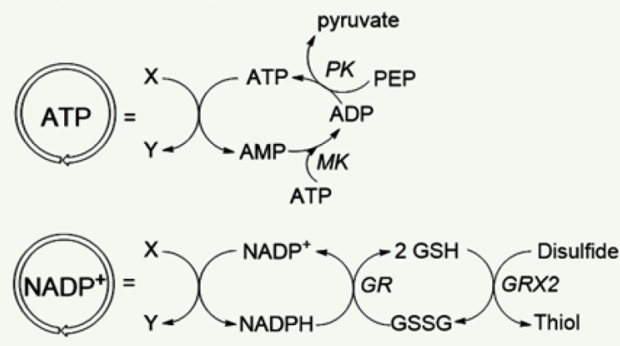

Figure 2. Strategy for the synthesis of 7,8-dihydrofolate $\left(\mathrm{H}_{2} \mathrm{~F}\right)$. Guanosine triphosphate (GTP) was made via the pentose phosphate and purine salvage pathways under hexokinase $(\mathrm{HK})$, glucose 6-phosphate dehydrogenase (G6PDH), 6-phosphogluconate dehydrogenase (6PGDH), phosphoriboisomerase (PRI), ribose-phosphate pyrophosphokinase (PRS), xanthine guanine phosphoribosyl transferase (XGPRT), guanylate kinase (GK), and pyruvate kinase (PK) catalysis. In the folate de novo pathway, GTP is converted to 7,8-dihydroneopterin (DHN) under catalysis by GTP cyclohydrolase I (GTP-CH-I), 7,8-dihydroneopterin pyrophosphatase (DHNTPase), and alkaline phosphatase (ALP); DHN is then converted to $\mathrm{H}_{2} \mathrm{~F}$ under catalysis by dihydroneopterin aldolase (DHNA), 6-hydroxymethyl 7,8-dihydropterin pyrophosphokinase (HPPK), and dihydropteroate synthase (DHPS). The additional enzymes myokinase (MK), glutathione reductase (GR), and glutaredoxin 2 (GRX2) are used for the regeneration of ATP and $\mathrm{NADP}^{+} .44,45$ The pterin atoms of $\mathrm{H}_{2} \mathrm{~F}$ derived from glucose (red) and guanine (blue) are highlighted. Details of each biosynthetic step are described in Figure S2.
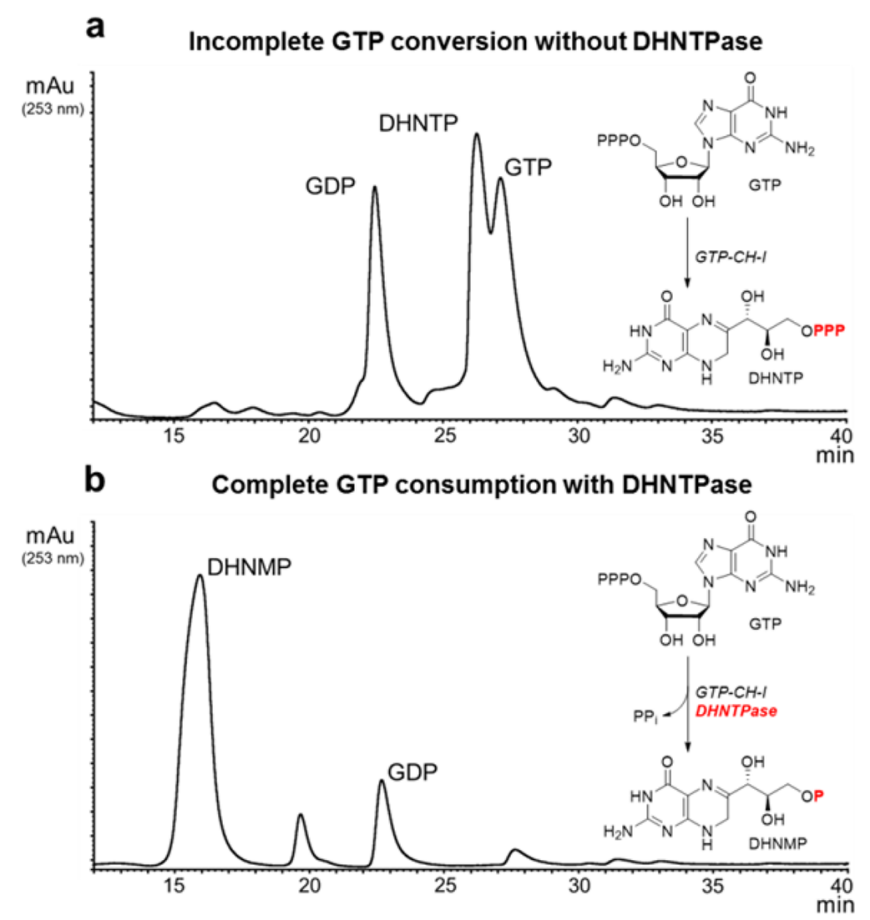

Figure 3. Conversion of guanosine triphosphate (GTP) into 7,8-dihydroneopterin triphosphate (DHNTP) and monophosphate (DHNMP). Shown are anion-exchange chromatography analyses of GTP incubated for $2 \mathrm{~h}$ at $37{ }^{\circ} \mathrm{C}$ with (a) GTP cyclohydrolase I (GTP-CH-I), which shows partial conversion to DHNTP, and (b) both GTP-CH-I and 7,8-dihydroneopterin triphosphate pyrophosphohydrolase (DHNTPase), resulting in essentially complete conversion to DHNMP. Production of guanosine diphosphate (GDP) is most likely due to the nonenzymatic hydrolysis of GTP during incubation.

p-aminobenzoyl-L-glutamate ( $p$ ABA-Glu). In the biosynthetic scheme of $\mathrm{H}_{2} \mathrm{~F}$ (Figure 2), $\mathrm{C} 2, \mathrm{C} 3$, and $\mathrm{C} 4$ of glucose correspond to $\mathrm{C} 7, \mathrm{C} 6$, and $\mathrm{C} 9$ of $\mathrm{H}_{2} \mathrm{~F}$ and $\mathrm{N} 1, \mathrm{C} 2, \mathrm{~N} 3, \mathrm{C} 4, \mathrm{C} 5, \mathrm{C} 6, \mathrm{~N} 7$, and $\mathrm{N} 9$ of guanine correspond to $\mathrm{N} 3, \mathrm{C} 2, \mathrm{~N} 1, \mathrm{C} 4 \mathrm{~b}, \mathrm{C} 4 \mathrm{a}, \mathrm{C} 4, \mathrm{~N} 5$, and $\mathrm{N} 8$ in $\mathrm{H}_{2} \mathrm{~F}$. GTP is the key intermediate in this synthetic pathway, connecting the purine salvage pathway to de novo folate biosynthesis. Accordingly, a minimum of 14 enzymes need to be assembled in vitro to produce $\mathrm{H}_{2} \mathrm{~F}$.

The GTP biosynthetic pathway is composed of enzymes from the pentose phosphate and purine salvage pathways (Figures 2 and S2). D-Glucose serves as the starting material, which is transformed into phosphoribose pyrophosphate (PRPP) in five steps that are catalyzed by hexokinase (HK), glucose 6-phosphate dehydrogenase (G6PDH), 6-phosphogluconate dehydrogenase $(6 \mathrm{PGDH})$, phosphoriboisomerase (PRI), and ribose-phosphate pyrophosphokinase (phosphoribosylpyrophosphate synthetase, PRS). ${ }^{44}$ PRPP is then combined with guanine to form GMP under xanthine guanine phosphoribosyl transferase (XGPRT) catalysis. The resulting GMP is converted to the corresponding nucleotide triphosphate in reactions catalyzed by guanylate kinase (GK) and pyruvate kinase (PK). Since HK and GK use ATP as the phosphate source, PK can also function as the recycling enzyme. On the other hand, PRS uses ATP as the pyrophosphate source, so myokinase (MK) was included to regenerate ATP from AMP. ${ }^{45}$ A significant amount of $\mathrm{NADP}^{+}$is also needed for GTP biosynthesis. Hence, the recently developed glutathione reductase (GR)/glutaredoxin 2 (GRX2) recycling system was used to regenerate the oxidized cofactor. ${ }^{44}$ The GR/GRX2 system uses disulfides like 2-hydroxyethyl 


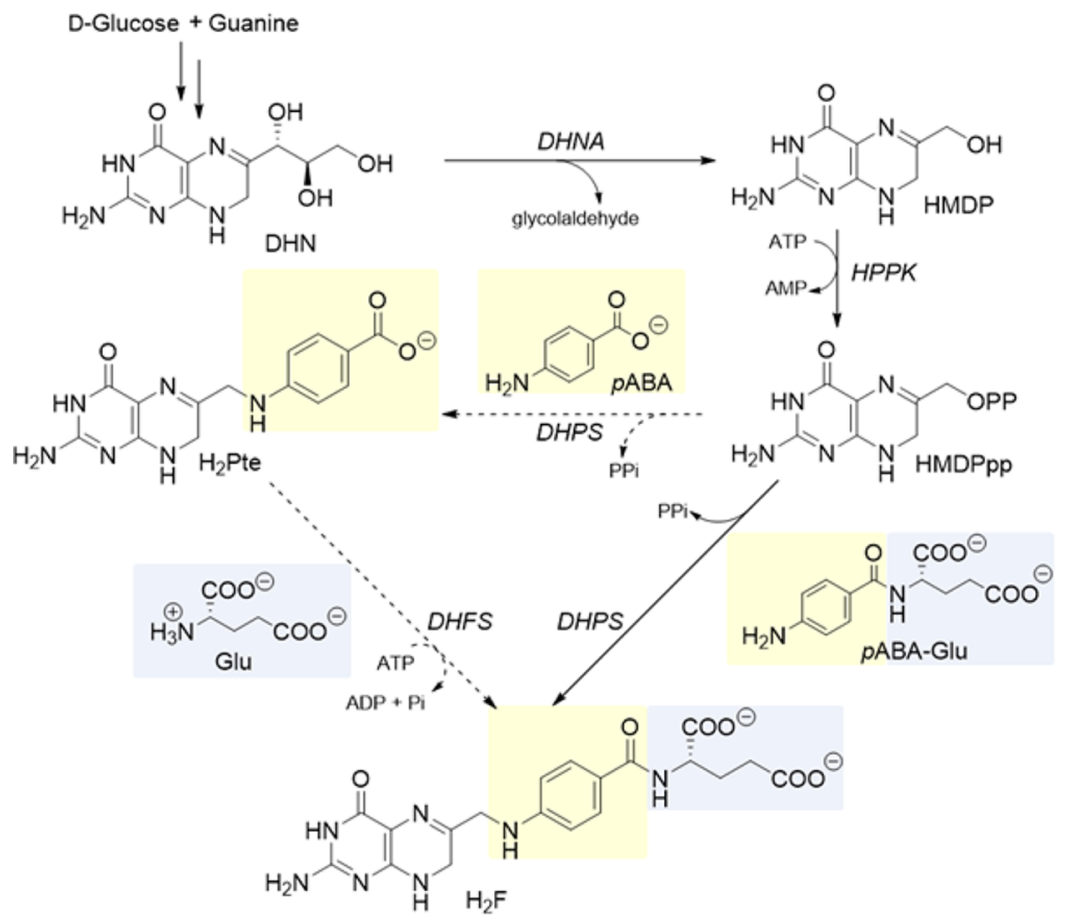

Figure 4. Conversion of 7,8-dihydroneopterin $(\mathrm{DHN})$ to dihydrofolate $\left(\mathrm{H}_{2} \mathrm{~F}\right)$. Dihydroneopterin aldolase (DHNA) catalyzes the transformation of DHN to 6-hydroxymethyl-7,8-dihydropterin (HMDP), which is pyrophosphorylated by 6-hydroxymethyl 7,8-dihydropterin pyrophosphokinase (HPPK). The resulting 6-hydroxymethyl-7,8-dihydropterin pyrophosphate (HMDPpp) is converted to $\mathrm{H}_{2} \mathrm{~F}$ by dihydropteroate synthase (DHPS), whose promiscuity allows the use of preassembled pABA-Glu as the substrate and the omission of dihydrofolate synthase (DHFS) in the in vitro synthetic pathway.

disulfide (HED or oxidized $\beta$-mercaptoethanol) or cystine as regenerating reagents and produces thiols as useful byproducts that protect the enzymes and intermediates from oxidative damage.

The conversion of GTP to DHNTP by GTP-CH-I marks the entry point of the folate de novo pathway. It has been reported that potassium and magnesium ions are positive allosteric effectors that can increase the rate of the GTP-CH-I reaction up to 5 -fold. ${ }^{46}$ The addition of these cations, however, was insufficient, as the reaction was found to be incomplete, giving a poor yield of DHNTP (Figure 3a). In folate de novo biosynthesis, dephosphorylation of DHNTP to 7,8-dihydroneopterin monophosphate (DHNMP) by DHNTP pyrophosphohydrolase (DHNTPase) is the biochemical step followed by the GTP-CH-I reaction (Figure 2) ${ }^{47,48}$ Knockout of the DHNTPase gene significantly impairs folate metabolism in E. coli, ${ }^{48}$ which suggests that DHNTP phosphohydrolysis is a key regulatory step in folate metabolism. In other words, the activity of GTP-CH-I is most likely inhibited by its own product, DHNTP, which therefore needs to be immediately converted to DHNMP in order to sustain the activity of GTP-CH-I. In the presence of DHNTPase, GTP-CH-I showed a marked rate enhancement (Figure S3), with nearly complete conversion of GTP and a high yield of DHNMP (Figure $3 b$ ).

Additional enzymes are needed to convert DHNMP into folate. To the best of our knowledge, the natural enzyme responsible for the conversion of DHNMP to 7,8-dihydroneopterin (DHN) is unknown, ${ }^{37,48}$ and alkaline phosphatase (ALP) was used instead as a surrogate. $\mathrm{DHN}$ is subjected to a retro-aldol reaction catalyzed by dihydroneopterin aldolase (DHNA) to yield 6-hydroxymethyl-7,8-dihydropterin (HMDP), ${ }^{49,50}$ which then reacts with ATP in the presence of 6-hydroxymethyl 7,8-dihydropterin pyrophosphokinase (HPPK) (Figure 4). ${ }^{51}$
In E. coli, the resulting intermediate, 6-hydroxymethyl-7,8dihydropterin pyrophosphate (HMDPpp), is first condensed with $p A B A$ and then with glutamate, catalyzed by dihydropteroate synthase (DHPS) ${ }^{52}$ and dihydrofolate synthase (DHFS), ${ }^{53}$ respectively, to finally generate $\mathrm{H}_{2} \mathrm{~F}$. However, DHPS accepts preassembled pABA-Glu as a substrate, ${ }^{54}$ so DHFS is not required in the in vitro reaction. The entire $\mathrm{H}_{2} \mathrm{~F}$ synthetic pathway requires only one purification step of the product, but ALP needs to be removed by ultrafiltration prior to the addition of DHNA, HPPK, and DHPS because the phosphatase can also catalyze the phosphorolysis of ATP and HMDPpp. Two additional modifications were made to further improve the overall yield. A $\mathrm{N}_{2}$-filled glovebox system was used because all reduced pterin-containing compounds, DHNTP, DHNMP, DHN, HMDP, HMDPpp, and the final product $\mathrm{H}_{2} \mathrm{~F}$, are oxygensensitive. ${ }^{41}$ Also, cystine was found to be the preferred reagent over HED for the $\mathrm{NADP}^{+}$regeneration system operated by GR and GRX2. Perhaps $\beta$-mercaptoethanol made from the reduction of HED interferes with other enzymatic reactions, such as the chelation of $\mathrm{Zn}^{2+}$ in GTP-CH-I. The total turnover numbers for the regeneration of ATP from $\mathrm{ADP}$ by pyruvate kinase and from AMP by pyruvate kinase/myokinase are both $\sim 100,{ }^{55}$ while the total turnover number for our GR/GRX2-based $\mathrm{NADP}^{+}$recycling system can reach $5 \times 10^{5} .^{44}$ In general, a typical biosynthetic cascade produced $6.6 \mathrm{mg}$ of $\mathrm{H}_{2} \mathrm{~F}$ from $9 \mathrm{mg}$ of glucose in an overall yield of $30 \%$, i.e., the average yield of each chemical transformation is in excess of $91 \%$.

Synthesis of Selectively Labeled Folates. Five isotopically labeled $\mathrm{H}_{2} \mathrm{Fs}$ were synthesized using the newly developed in vitro pathway (Figure 5a). Liquid chromatography-high-resolution mass spectrometry (LC-HRMS) analysis of $\left[6-{ }^{13} \mathrm{C}\right] \mathrm{H}_{2} \mathrm{~F}$, produced from $\left[3-{ }^{13} \mathrm{C}\right] \mathrm{D}$-glucose, showed an increase of $\sim 1$ $\mathrm{amu} ;{ }^{13} \mathrm{C}$ NMR spectroscopy revealed a singlet at $152 \mathrm{ppm}$. 
a
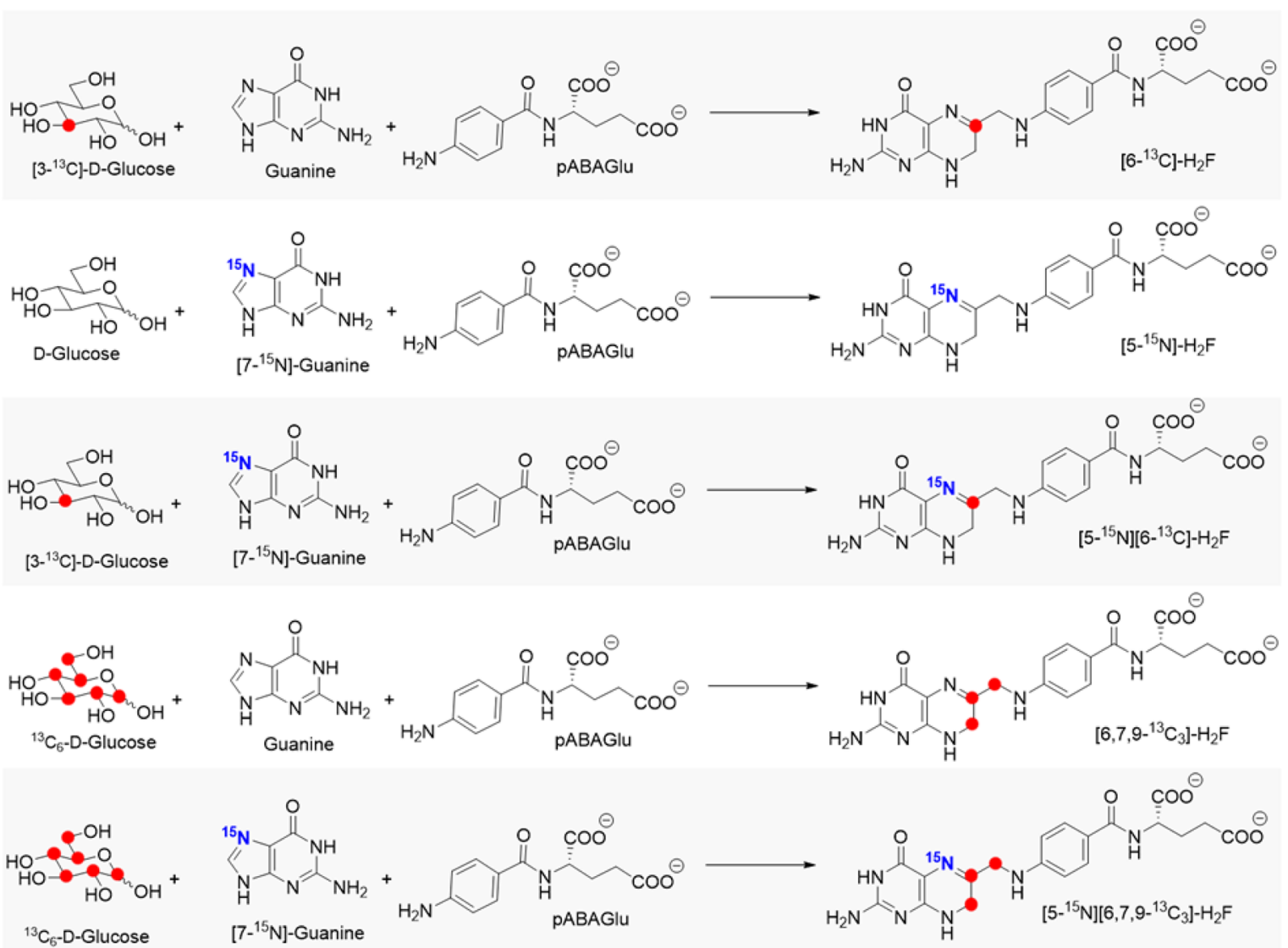

Guanine<smiles>CC(C)(C)[18O]C(=O)[O-]</smiles><smiles></smiles>

\section{b}

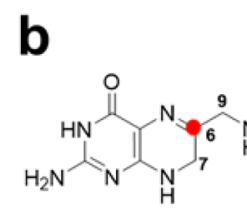
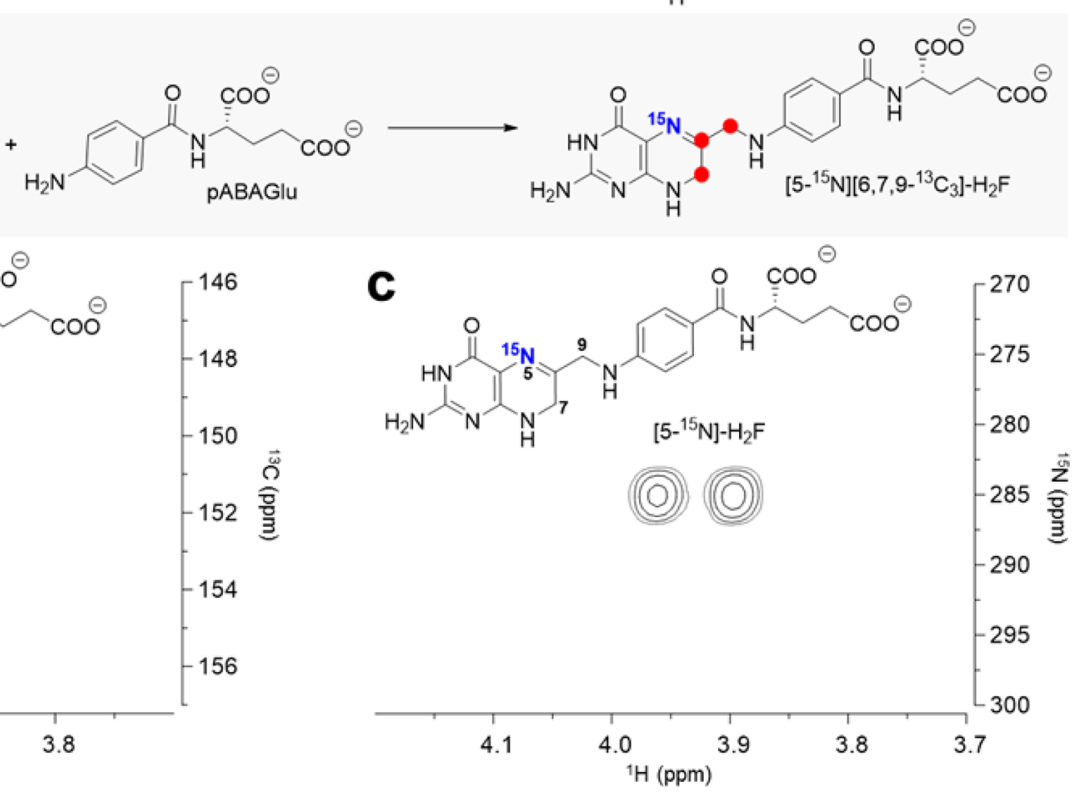

Figure 5. $\mathrm{H}_{2} \mathrm{Fs}$ labeled with stable isotopes on the pterin ring system. (a) Patterns of isotopic distribution are determined by the starting material isotopic enrichment used during $\mathrm{H}_{2} \mathrm{~F}$ biosynthetic assembly. (b) ${ }^{1} \mathrm{H},{ }^{13} \mathrm{C} \mathrm{HMBC}$ and $(\mathrm{c}){ }^{1} \mathrm{H},{ }^{15} \mathrm{~N}$ HMBC spectra of $\left[6-{ }^{13} \mathrm{C}\right] \mathrm{H}_{2} \mathrm{~F}$ and $\left[5-{ }^{15} \mathrm{~N}\right] \mathrm{H}_{2} \mathrm{~F}$. Protons attached to C7 $(3.95 \mathrm{ppm})$ and C9 $(3.87 \mathrm{ppm})$ correlate to C6 $(152 \mathrm{ppm})$ or N5 $(285 \mathrm{ppm}){ }^{1} \mathrm{H}$ NMR spectra of all compounds and additional $2 \mathrm{D}$ NMR characterization of $\left[5-{ }^{15} \mathrm{~N}\right]\left[6-{ }^{13} \mathrm{C}\right] \mathrm{H}_{2} \mathrm{~F},\left[6,7,9-{ }^{13} \mathrm{C}_{3}\right] \mathrm{H}_{2} \mathrm{~F}$ and $\left[5-{ }^{15} \mathrm{~N}\right]\left[6,7,9-{ }^{13} \mathrm{C}_{3}\right] \mathrm{H}_{2} \mathrm{~F}$ are reported in Figures $\mathrm{S} 12-\mathrm{S} 15$. HRMS data for all of the compounds are given in Table S3 and Figures S16-S21. Isotopic enrichment was calculated to be at least $97 \%$ from the mass spectrometric data (as illustrated in Figures S22-S24).

Additionally, long-range coupling between $6-{ }^{13} \mathrm{C}$ and protons on $\mathrm{C} 7$ and $\mathrm{C} 9$ of $\left[6-{ }^{13} \mathrm{C}\right] \mathrm{H}_{2} \mathrm{~F}$ were observed in the ${ }^{1} \mathrm{H},{ }^{13} \mathrm{C}$ HMBC spectrum (Figure $5 \mathrm{~b}$ ).

To incorporate an ${ }^{15} \mathrm{~N}$ label into the pterin moiety at N5, $\left[7-{ }^{15} \mathrm{~N}\right]$ guanine was used. The resulting product showed $\sim 1 \mathrm{amu}$ increase in LC-HRMS analysis and an ${ }^{15} \mathrm{~N}$ signal at $285 \mathrm{ppm}$ coupling to $\mathrm{C} 7$ and $\mathrm{C} 9$ protons in the ${ }^{1} \mathrm{H},{ }^{15} \mathrm{~N}$ HMBC spectrum (Figure 5c).

When $\left[3-{ }^{13} \mathrm{C}\right] \mathrm{D}$-glucose and $\left[7-{ }^{15} \mathrm{~N}\right]$ guanine were combined to produce $\left[5-{ }^{15} \mathrm{~N}\right]\left[6-{ }^{13} \mathrm{C}\right] \mathrm{H}_{2} \mathrm{~F}$, a mass increase of $\sim 2$ amu was measured. The ${ }^{13} \mathrm{C}$ NMR spectrum showed a doublet at $152 \mathrm{ppm}$ with a coupling constant ${ }^{1} J_{\mathrm{CN}}$ of $7.5 \mathrm{~Hz}$; long-range coupling between the protons on $\mathrm{C} 7$ and $\mathrm{C} 9$ was observed in the ${ }^{1} \mathrm{H},{ }^{13} \mathrm{C}$ HMBC and ${ }^{1} \mathrm{H},{ }^{15} \mathrm{~N}$ HMBC spectra (see the Supporting Information), indicating that both $\mathrm{N} 5$ and $\mathrm{C} 6$ of $\mathrm{H}_{2} \mathrm{~F}$ were isotopically enriched.

Similarly, $\left[6,7,9-{ }^{13} \mathrm{C}_{3}\right] \mathrm{H}_{2} \mathrm{~F}$ and $\left[5-{ }^{15} \mathrm{~N}\right]\left[6,7,9-{ }^{13} \mathrm{C}_{3}\right] \mathrm{H}_{2} \mathrm{~F}$ were synthesized from ${ }^{13} \mathrm{C}_{6}$-D-glucose and $\left[7-{ }^{15} \mathrm{~N}\right]$ guanine, and their identities were confirmed by HRMS and NMR spectroscopy (see the Supporting Information).

Heavy-Atom Kinetic Isotope Effects on the Reaction Catalyzed by EcDHFR. The preparation of ${ }^{13} \mathrm{C}$ - and ${ }^{15} \mathrm{~N}$-labeled 
dihydrofolates allowed the measurement of heavy-atom isotope effects for the reactions catalyzed by dihydrofolate reductase (DHFR), a key enzyme in one-carbon metabolism and a validated target for the treatment of bacterial infections, malaria, and cancer. ${ }^{56}$ DHFR catalyzes the reduction of $\mathrm{H}_{2} \mathrm{~F}$ to $\mathrm{H}_{4} \mathrm{~F}$ via transfer of the pro- $R$ hydride from $\mathrm{C} 4$ of NADPH to the $R e$ face on $\mathrm{C} 6$ accompanied by protonation of $\mathrm{N} 5$ of $\mathrm{H}_{2} \mathrm{~F}$ (Figure 6). ${ }^{57,58}$

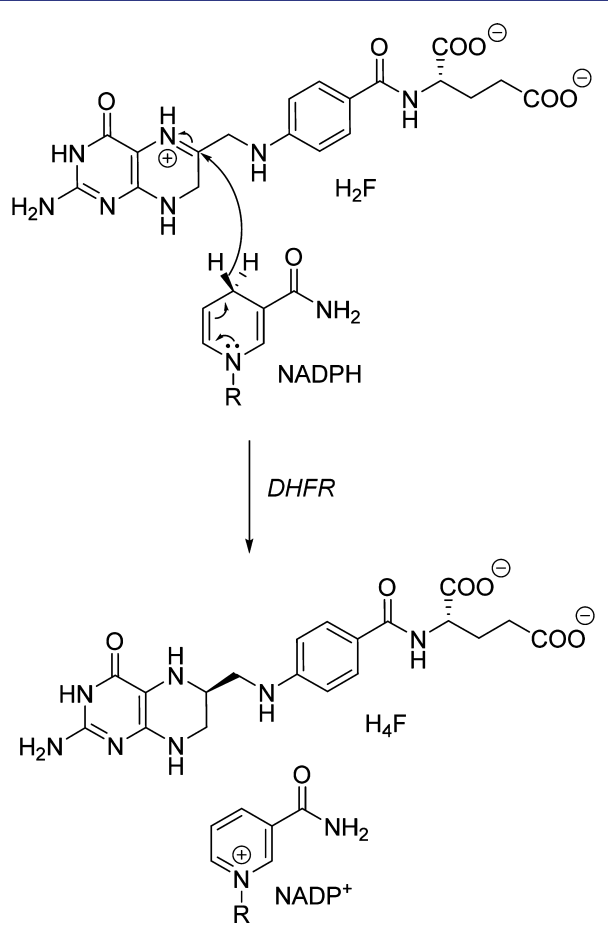

Figure 6. Reduction of 7,8-dihydrofolate $\left(\mathrm{H}_{2} \mathrm{~F}\right)$ to 5,6,7,8-tetrahydrofolate $\left(\mathrm{H}_{4} \mathrm{~F}\right)$ catalyzed by dihydrofolate reductase (DHFR).

Several aspects of the reaction mechanism warrant additional investigation. In particular, the transition state structure and the order of chemical transformation events have not been fully determined. ${ }^{59,60}$ The active site of DHFR provides a favorable environment for protonation of N5 by elevating the $\mathrm{p} K_{\mathrm{a}}$ from 2.6 to 6.5 and using an active-site water as the proton source. ${ }^{61,62}$ Solvent and hydrogen KIE measurements combined with sitedirected mutagenesis have suggested a stepwise mechanism in which protonation precedes hydride transfer. ${ }^{63,64}$ However, $\mathrm{D}_{2} \mathrm{O}$ increases the viscosity of the reaction buffer relative to $\mathrm{H}_{2} \mathrm{O}, 65,66$ and site-directed modification can alter the catalytic behavior of an enzyme. ${ }^{67}$ Thus, additional mechanistic investigations are needed to establish the order of events. Since isotopic substitution does not alter the chemistry of the reaction but only the kinetics, $\left[6-{ }^{13} \mathrm{C}\right] \mathrm{H}_{2} \mathrm{~F}$ and $\left[5-{ }^{15} \mathrm{~N}\right] \mathrm{H}_{2} \mathrm{~F}$ were used to measure the ${ }^{15} \mathrm{~N}$ and ${ }^{13} \mathrm{C}$ heavy-atom kinetic isotope effects. Pre-steadystate kinetic measurements at $15{ }^{\circ} \mathrm{C}$ by fluorescence resonance energy transfer from the active-site tryptophan in DHFR to the reduced cofactor yield first-order hydride transfer rate constants with an accuracy of up to $0.7 \%$ (Figures S25-S27 and Table S4). While a ${ }^{13} \mathrm{C} \mathrm{KIE}$ of $1.015 \pm 0.006$ was observed for the reduction of $\left[6-{ }^{13} \mathrm{C}\right] \mathrm{H}_{2} \mathrm{~F}$, the corresponding ${ }^{15} \mathrm{~N} \mathrm{KIE}$ for $\left[5-{ }^{15} \mathrm{~N}\right] \mathrm{H}_{2} \mathrm{~F}$ was essentially unity $(0.999 \pm 0.006)$ under the same conditions. To confirm this finding, $\left[5-{ }^{15} \mathrm{~N}\right]\left[6-{ }^{13} \mathrm{C}\right] \mathrm{H}_{2} \mathrm{~F}$ was used to probe both positions at the same time, and the measured value for the corresponding multiple heavy-atom KIE was $1.014 \pm 0.008$, which is statistically identical to that obtained when the substrate was labeled with ${ }^{13} \mathrm{C}$ only.
The observed ${ }^{15} \mathrm{~N}$ KIE on hydride transfer indicates that protonation of N5 is not isotopically sensitive, likely because it is not rate-limiting under pre-steady-state conditions (as the reaction is essentially irreversible, ${ }^{58}$ the observed KIE will tend to unity rather than to the equilibrium isotope effect). ${ }^{22}$ On the other hand, the measured ${ }^{13} \mathrm{C}$ KIE indicates that the hydride transfer step is rate-determining. This strongly suggests a stepwise mechanism. If the protonation and hydride transfer steps were concerted, ${ }^{15} \mathrm{~N}$ - and ${ }^{13} \mathrm{C}$-labeled $\mathrm{H}_{2} \mathrm{Fs}$ should both yield measurable KIEs; ${ }^{19,21,22}$ this interdependence may also lead to an additive effect in the multiple heavy-atom isotope effect measurement with the double-labeled substrate. ${ }^{19,21,22}$ In other words, our results suggest that the pre-steady-state kinetic measurement at $\mathrm{pH} 7.0$ reveals only the step of hydride transfer because protonation of $\mathrm{N} 5$ is in rapid equilibrium and the ensemble of reaction-ready conformations is mostly populated with protonated $\mathrm{H}_{2} \mathrm{~F}$. Importantly, these results confirm the validity of previous solvent KIE and site-directed mutagenesis studies, which also concluded that the sequence of chemical events (protonation and hydride transfer) is distinct and strictly ordered. ${ }^{64,68}$ Overall, the results provided here strongly support a mechanism where protonation and hydride transfer are independent of each other and occur in a stepwise fashion.

\section{CONCLUSIONS}

Dihydrofolate was produced enzymatically in an easy one-pot, high-yielding reaction sequence from glucose, guanine, and $p A B A-G l u$ that required only a single purification step. Potential problems with individual steps during the synthesis could be overcome through the use of a one-pot reaction. This methodology can be used to generate dihydrofolates labeled in specific positions with stable isotopes with average overall yields of $>30 \%$, facilitating many applications in cell biology and mechanistic enzymology. ${ }^{27-29,61,69,70}$ For the first time, heavyatom KIEs for the DHFR-catalyzed reduction of $\mathrm{H}_{2} \mathrm{~F}$ could be measured to provide strong support for a stepwise reduction of the substrate in which protonation at N5 and hydride transfer from $\mathrm{C} 4$ of the NADPH to $\mathrm{C} 6$ of protonated dihydrofolate proceed independently. This chemoenzymatic pterin synthesis can be integrated into other enzymatic procedures to generate folate derivatives ${ }^{31,32}$ and other high-value natural products that are not easily accessible by conventional synthesis. ${ }^{71}$ It can be applied to nutritional, medical, and cell-biological research to address questions of in vivo bioavailability and to explore the kinetics of folate metabolism in intact cells and organisms. ${ }^{70,72-76}$

\section{ASSOCIATED CONTENT}

\section{S Supporting Information}

The Supporting Information is available free of charge on the ACS Publications website at DOI: 10.1021/jacs.7b06358.

Full experimental procedures and supplementary figures and tables (PDF)

\section{AUTHOR INFORMATION}

\section{Corresponding Author}

*allemannrk@cardiff.ac.uk

ORCID

William M. Dawson: 0000-0003-2710-6879

E. Joel Loveridge: 0000-0002-8528-4019

Rudolf K. Allemann: 0000-0002-1323-8830 


\section{Present Addresses}

${ }^{\dagger}$ W.M.D.: School of Chemistry, University of Bristol, Cantock's Close, Bristol BS8 1TS, United Kingdom.

${ }^{\ddagger}$ E.J.L.: Department of Chemistry, Swansea University, Singleton Park, Swansea SA2 8PP, United Kingdom.

\section{Notes}

The authors declare no competing financial interest.

\section{ACKNOWLEDGMENTS}

We are grateful to Dr. James R. Williamson (Scripps Research Institute) for his gift of prsA. The help of Dr. Rob Jenkins and Mr. Thomas Williams with mass spectrometry is gratefully acknowledged. This work was supported by Cardiff University through a President's Research Scholarship to A.A. and the UK's Biotechnology and Biological Sciences Research Council (BBSRC) through Grants BB/J005266/1 and BB/L020394/1 to R.K.A.

\section{REFERENCES}

(1) Hoffbrand, A. V.; Weir, D. G. Br. J. Haematol. 2001, 113, 579-589.

(2) Fox, J. T.; Stover, P. J. Vitam. Horm. 2008, 79, 1-44.

(3) Basu, P.; Burgmayer, S. J. Coord. Chem. Rev. 2011, 255, 1016-1038.

(4) Schwarz, G.; Mendel, R. R.; Ribbe, M. W. Nature 2009, 460, 839847.

(5) Thöny, B.; Auerbach, G.; Blau, N. Biochem. J. 2000, 347, 1-16.

(6) Pfleiderer, W. Adv. Exp. Med. Biol. 1993, 338, 1-16.

(7) Noguchi, Y.; Ishii, A.; Matsushima, A.; Haishi, D.; Yasumuro, K.; Moriguchi, T.; Wada, T.; Kodera, Y.; Hiroto, M.; Nishimura, H.; Sekine, M.; Inada, Y. Mar. Biotechnol. 1999, 1, 207-210.

(8) Ducker, G. S.; Rabinowitz, J. D. Cell Metab. 2017, 25, 27-42.

(9) Murima, P.; McKinney, J. D.; Pethe, K. Chem. Biol. 2014, 21, $1423-1432$.

(10) Nzila, A.; Ward, S. A.; Marsh, K.; Sims, P. F.; Hyde, J. E. Trends Parasitol. 2005, 21, 292-298.

(11) Nzila, A.; Ward, S. A.; Marsh, K.; Sims, P. F.; Hyde, J. E. Trends Parasitol. 2005, 21, 334-339.

(12) Locasale, J. W. Nat. Rev. Cancer 2013, 13, 572-583.

(13) Yang, M.; Vousden, K. H. Nat. Rev. Cancer 2016, 16, 650-662.

(14) WHO Model Lists of Essential Medicines, 19th ed.; World Health Organization: Geneva, Switzerland, 2015.

(15) Zhao, R.; Goldman, I. D. Oncogene 2003, 22, 7431-7457.

(16) Müller, I. B.; Hyde, J. E. Mol. Biochem. Parasitol. 2013, 188, 6377.

(17) Sköld, O. Sulfonamides and Trimethorpim. In Antimicrobial Drug Resistance; Mayers, D. L., Ed.; Humana Press: New York, 2009; Vol. 1, pp 259-269.

(18) Copeland, R. A.; Harpel, M. R.; Tummino, P. J. Expert Opin. Ther. Targets 2007, 11, 967-978.

(19) Cleland, W. W. Arch. Biochem. Biophys. 2005, 433, 2-12.

(20) Vardi-Kilshtain, A.; Nitoker, N.; Major, D. T. Arch. Biochem. Biophys. 2015, 582, 18-27.

(21) Cook, P. F. Isot. Environ. Health Stud. 1998, 34, 3-17.

(22) O'Leary, M. H. Annu. Rev. Biochem. 1989, 58, 377-401.

(23) Wharton, C. W. Nat. Prod. Rep. 2000, 17, 447-453.

(24) Palmer, A. G. Acc. Chem. Res. 2015, 48, 457-65.

(25) Schramm, V. L. Acc. Chem. Res. 2015, 48, 1032-1039.

(26) Maunder, P.; Finglas, P.; Mallet, A.; Mellon, F.; Razzaque, M.; Ridge, B.; Vahteristo, L.; Witthoft, C. J. Chem. Soc., Perkin Trans. 1 1999, 1311-1323.

(27) Cocco, L.; Groff, J. P.; Temple, C.; Montgomery, J. A.; London, R. E.; Matwiyoff, N. A.; Blakley, R. L. Biochemistry 1981, 20, 3972-3978.

(28) Selinsky, B. S.; Perlman, M. E.; London, R. E.; Unkefer, C. J.; Mitchell, J.; Blakley, R. L. Biochemistry 1990, 29, 1290-1296.

(29) Cheung, H. T. A.; Birdsall, B.; Frenkiel, T. A.; Chau, D. D.; Feeney, J. Biochemistry 1993, 32, 6846-6854.

(30) Cowart, M.; Falzone, C. J.; Benkovic, S. J. J. Labelled Compd. Radiopharm. 1994, 34, 67-71.
(31) Saeed, M.; Tewson, T. J.; Erdahl, C. E.; Kohen, A. Nucl. Med. Biol. 2012, 39, 697-701.

(32) Curthoys, N. P.; Scott, J. M.; Rabinowitz, J. C. J. Biol. Chem. 1972, 247, 1959-1964.

(33) Moran, R. G.; Keyomarsi, K.; Colman, P. D. Methods Enzymol. 1986, 122, 309-312.

(34) Gräwert, T.; Fischer, M.; Bacher, A. IUBMB Life 2013, 65, 310322.

(35) Fischer, M.; Thöny, B.; Leimkühler, S. The biosynthesis of folate and pterins and their enzymology. In Comprehensive Natural Products II; Mander, L., Liu, H.-W., Eds.; Elsevier: Oxford, U.K., 2010; Vol. 7, pp 599-648.

(36) Rebelo, J.; Auerbach, G.; Bader, G.; Bracher, A.; Nar, H.; Hösl, C.; Schramek, N.; Kaiser, J.; Bacher, A.; Huber, R.; Fischer, M. J. Mol. Biol. 2003, 326, 503-516.

(37) Burg, A. W.; Brown, G. M. Chem. Commun. 1968, 243, 23492358.

(38) Yim, J. J.; Brown, G. M. J. Biol. Chem. 1976, 251, 5087-5094.

(39) Illarionova, V.; Eisenreich, W.; Fischer, M.; Haussmann, C.; Romisch, W.; Richter, G.; Bacher, A. J. Biol. Chem. 2002, 277, 2884128847.

(40) Schramek, N.; Bracher, A.; Bacher, A. J. Biol. Chem. 2001, 276, 2622-2626.

(41) Dantola, M. L.; Vignoni, M.; Capparelli, A. L.; Lorente, C.; Thomas, A. H. Helv. Chim. Acta 2008, 91, 411-425.

(42) Schultheisz, H. L.; Szymczyna, B. R.; Scott, L. G.; Williamson, J. R. ACS Chem. Biol. 2008, 3, 499-511.

(43) Tolbert, T. J.; Williamson, J. R. J. Am. Chem. Soc. 1996, 118, 7929-7940.

(44) Angelastro, A.; Dawson, W. M.; Luk, Y. P. L.; Allemann, R. K. ACS Catal. 2017, 7, 1025-1029.

(45) Gross, A.; Abril, O.; Lewis, J. M.; Geresh, S.; Whitesides, G. M. J. Am. Chem. Soc. 1983, 105, 7428-7435.

(46) Schoedon, G.; Redweik, U.; Frank, G.; Cotton, R. G.; Blau, N. Eur. J. Biochem. 1992, 210, 561-568.

(47) Suzuki, Y.; Brown, G. M. J. Biol. Chem. 1974, 249, 2405-2410.

(48) Gabelli, S. B.; Bianchet, M. A.; Xu, W.; Dunn, C. A.; Niu, Z. D.; Amzel, L. M.; Bessman, M. J. Structure 2007, 15, 1014-1022.

(49) Mathis, J. B.; Brown, G. M. J. Biol. Chem. 1970, 245, 3015-3025.

(50) Wang, Y.; Li, Y.; Yan, H. Biochemistry 2006, 45, 15232-15239.

(51) Derrick, J. P. Vitam. Horm. 2008, 79, 411-433.

(52) Weisman, R. A.; Brown, G. M. J. Biol. Chem. 1964, 239, 326-331.

(53) Griffin, M. J.; Brown, G. M. J. Biol. Chem. 1964, 239, 310-316.

(54) Richey, D. P.; Brown, G. M. Biochim. Biophys. Acta, Gen. Subj. 1970, 222, 237-239.

(55) Chenault, H. K.; Simon, E. S.; Whitesides, G. M. Biotechnol. Genet. Eng. Rev. 1988, 6, 221-270.

(56) Schweitzer, B. I.; Dicker, A. P.; Bertino, J. R. FASEB J. 1990, 4, 2441-2452.

(57) Charlton, P. A.; Young, D. W.; Birdsall, B.; Feeney, J.; Roberts, G. C. K. J. Chem. Soc., Perkin Trans. 1 1985, 1349-1353.

(58) Fierke, C. A.; Johnson, K. A.; Benkovic, S. J. Biochemistry 1987, 26, 4085-4092.

(59) Shrimpton, P.; Allemann, R. K. Protein Sci. 2002, 11, 1442-1451.

(60) Shrimpton, P.; Mullaney, A.; Allemann, R. K. Proteins: Struct., Funct., Genet. 2003, 51, 216-223.

(61) Chen, Y. Q.; Kraut, J.; Blakley, R. L.; Callender, R. Biochemistry 1994, 33, 7021-7026.

(62) Wan, Q.; Bennett, B. C.; Wilson, M. A.; Kovalevsky, A.; Langan, P.; Howell, E. E.; Dealwis, C. Proc. Natl. Acad. Sci. U. S. A. 2014, 111, 18225-18230.

(63) Stone, S. R.; Morrison, J. F. Biochemistry 1984, 23, 2753-2758.

(64) Liu, C. T.; Francis, K.; Layfield, J. P.; Huang, X.; Hammes-Schiffer, S.; Kohen, A.; Benkovic, S. J. Proc. Natl. Acad. Sci. U. S. A. 2014, 111, 18231-18236.

(65) Cioni, P.; Strambini, G. B. Biophys. J. 2002, 82, 3246-3253.

(66) Schowen, K. B.; Schowen, R. L. Methods Enzymol. 1982, 87, 551606.

(67) Peracchi, A. Trends Biochem. Sci. 2001, 26, 497-503. 
(68) Loveridge, E. J.; Behiry, E. M.; Swanwick, R. S.; Allemann, R. K. J. Am. Chem. Soc. 2009, 131, 6926-6927.

(69) Deng, H.; Callender, R.; Howell, E. J. Biol. Chem. 2001, 276, 48956-48960.

(70) Mönch, S.; Netzel, M.; Netzel, G.; Rychlik, M. Anal. Biochem. 2010, 398, 150-160.

(71) McCarty, R. M.; Somogyi, A.; Lin, G.; Jacobsen, N. E.; Bandarian, V. Biochemistry 2009, 48, 3847-3852.

(72) Gregory, J. F., III; Williamson, J.; Liao, J.-F.; Bailey, L. B.; Toth, J. P. J. Nutr. 1998, 128, 1896-1906.

(73) Gregory, J. F., III. J. Nutr. 2001, 131, 1376S-1382S.

(74) Gregory, J. F., III; Quinlivan, E. P. Annu. Rev. Nutr. 2002, 22, 199220.

(75) Kopp, M.; Morisset, R.; Koehler, P.; Rychlik, M. PLoS One 2016, 11, $\mathrm{e} 0156610$.

(76) de Ambrosis, A.; Vishnumohan, S.; Paterson, J.; Haber, P.; Arcot, J. Eur. J. Clin. Nutr. 2017, 71, 103-106. 